\title{
TOPICS
}

Topics in Cognitive Science 00 (2021) 1-24

(C) 2021 Cognitive Science Society LLC

ISSN: $1756-8765$ online

DOI: $10.1111 /$ tops. 12549

This article is part of the topic "The Cognitive Science of Tools and Techniques" Wayne D. Gray, François Osiurak and Richard Heersmink (Topic Editors). For a full listing of topic papers, see http://onlinelibrary.wiley.com/journal/10.1111/(ISSN)1756-8765/earlyview.

\section{Varieties of Artifacts: Embodied, Perceptual, Cognitive, and Affective}

\author{
Richard Heersmink \\ Department Department of Politics, Media \& Philosophy, La Trobe University
}

Received 6 January 2021; received in revised form 14 May 2021; accepted 19 May 2021

\begin{abstract}
The primary goal of this essay is to provide a comprehensive overview and analysis of the various relations between material artifacts and the embodied mind. A secondary goal of this essay is to identify some of the trends in the design and use of artifacts. First, based on their functional properties, I identify four categories of artifacts co-opted by the embodied mind, namely (a) embodied artifacts, (b) perceptual artifacts, (c) cognitive artifacts, and (d) affective artifacts. These categories can overlap and so some artifacts are members of more than one category. I also identify some of the techniques (or skills) we use when interacting with artifacts. Identifying these categories of artifacts and techniques allows us to map the landscape of relations between embodied minds and the artifactual world. Second, having identified categories of artifacts and techniques, this essay then outlines some of the trends in the design and use of artifacts, focusing on neuroprosthetics, brain-computer interfaces, and personalization algorithms nudging their users toward particular epistemic paths of information consumption.
\end{abstract}

Keywords: Situated cognition; Perception; Embodiment; Cognition; Affect; Interaction; Embodied artifact; Perceptual artifact; Cognitive artifact; Affective artifact; Artificial intelligence; Algorithms

Correspondence should be sent to Richard Heersmink, Department of Politics, Media \& Philosophy, La Trobe University, Melbourne 3083, Australia. E-mail: richard.heersmink@gmail.com 


\section{Introduction}

Our success as a species partly depends on our capacity to modify the environment and to create and use artifacts. While some other animal species can make and use artifacts and, in that sense, are on the same spectrum as we are, it is equally important to acknowledge that humans are far removed from other species on that spectrum. How humans build and use artifacts is unique in the animal kingdom in terms of complexity, variety, and the principles involved in the design process. ${ }^{1}$ The agential, perceptual, cognitive, and affective relevancy of how we create and skillfully interact with the artifactual world to achieve our aims constitutes a large part of what makes us uniquely human. Andy Clark (2003) has argued that we are "natural-born cyborgs"2: creatures that naturally form hybrid systems with technological artifacts that are incorporated into our motor, perceptual, and cognitive systems. ${ }^{3}$ On this notion, we do not merely make and use artifacts to achieve our aims, artifacts also shape us in important ways and, in some cases, even constitute us (Clark, 2003; Heersmink, 2018b). Artifacts are so deeply integrated into our motor, perceptual, cognitive, and affective systems that they define our capabilities, mind, and identity in important ways.

Situated and 4E cognition theorists have put our relation to environmental objects and structures center stage as a unit of analysis for the cognitive sciences. The paradigm shift from conceptualizing the mind as a purely internal affair to seeing it as embodied and shaped by and strongly connected to the environment is well under way (Clark, 2003, 2008; Finley, Naaz, \& Goh, 2018; Hipolito, Clowes \& Gartner 2021; Hutchins, 1995; Newen, De Bruin \& Gallagher 2018; Norman, 1993; Robbins \& Aydede 2008; Sternberg \& Preiss 2005). Many studies, both conceptual and empirical, in the situated and 4E cognition literature focus on our relation to particular artifacts (e.g., Brey, 2005; Clark \& Chalmers 1998; Hutchins, 1995; Kirsh \& Maglio 1994; Sutton, 2010). There are also taxonomies of particular classes of artifacts such as cognitive artifacts (Brey, 2005; Casati, 2017; Fasoli, 2018a; Heersmink, 2013a; Nickerson, 2005). However, a comprehensive general taxonomy of artifacts and the way they are co-opted by the human embodied mind is lacking.

The primary goal of this essay is therefore to map the landscape of relations between embodied minds and various kinds of artifacts by identifying four categories of artifacts, namely those that aid us in achieving our (a) motor, (b) perceptual, (c) cognitive, and (d) affective tasks/goals. These categories are not meant to have clear and sharp boundaries, but sometimes overlap. I also identify four kinds of techniques (or skills), which are ways or methods to achieve our aims. These techniques often involve the use of artifacts, but not always. Identifying these artifacts and techniques allows us to map and better understand the landscape of relations between embodied minds and the artifactual world. ${ }^{4}$ This, in turn, provides us with a broader picture of humans as natural born cyborgs, showing how humans use embodied, perceptual, cognitive, and affective artifacts to achieve their aims, complete their tasks, and regulate their emotions.

This paper has the following structure. In Section 2, I define some of the key concepts in this paper, namely tool, artifact, naturefact, and technique. I will then hone in on embodied 
artifacts (Section 3), perceptual artifacts (Section 4), cognitive artifacts (Section 5), and affective artifacts (Section 6). Having described these various kinds of artifacts, I will problematize the boundaries between these categories of artifacts (Section 7). Finally, in Section 8, I outline some trends regarding the development and use of artifacts, focusing on neuroprosthetics, brain-computer interfaces, personalization algorithms.

\section{Artifacts and techniques}

This paper is part of a special issue on "the cognitive science of tools and techniques." The Oxford Dictionary defines a tool as "a handheld device that aids in accomplishing a task." My focus in this paper will be broader than handheld devices. So, instead, I will use the term "artifact" to refer to material objects or structures that are made to be used to achieve an aim $^{5}$ (Preston, 2018). While some artifacts are tools, in that they are handheld devices such as, for example, a hammer, most are not. ${ }^{6}$ An artifact is any material product of human agency and may range from simple, singular artifacts like hammers, glasses, and notebooks to more complex, composite artifacts such as brain-computer interfaces, skyscrapers, and satellite systems. This notion goes back to Aristotle's (1984) distinction between things that exist through human agency and through nature. Artifacts come into existence through human agency, whereas other objects and structures come into existence through nonagential forces in nature. ${ }^{7}$ Note that this definition includes less traditional artifacts such as perfumes, food, songs, films, algorithms, and computer games.

Another distinctive feature of artifacts is that they are "for something," that is, they have a "function" (Houkes \& Vermaas 2010; Preston, 2013). An artifact's function is usually the effect it has on the world or on the user. A hammer is for hammering nails into materials, glasses are for perceiving the world more clearly, maps are for aiding their user in navigating, and guitars are for making music and expressing one's feelings. Often, artifacts are intentionally designed and made to perform a particular function. Hammers, glasses, maps, and guitars are designed, made, and used for helping their users to hammer, perceive, navigate, and express themselves. Such functions may be referred to as "proper functions." However, sometimes we improvise and attribute a function to an artifact that it was not designed or made for. I may use a hammer as a weapon, glasses as a diadem, maps as a placemat, and a guitar as a design piece to put in my living room. We use artifacts in ways that they were not initially intended for. Such functions may be referred to as "improvised functions." rizing, we can characterize artifacts as functional entities made, modified, or improvised to have a certain effect on the world or on the user. ${ }^{9}$

The focus in this paper is on artifacts used for acting on the world, sensing, cognizing, and feeling. Such artifacts can have both proper and improvised functions. It is, however, important to point out that we also use naturally occurring objects and structures for these purposes. For example, we can use a rock to hammer a nail into a wall, a stick to sense the world, the sun to navigate, and we can look at a starry night sky to create a feeling of awe and wonder. Following Hilpinen (2011), we can refer to naturally occurring objects and structures used for human purposes as "naturefacts," constituting a category between artifacts and 
naturally occurring objects and structures. While it is important to acknowledge that we also use naturefacts, given our highly technological world, the vast majority of our interactions are with artifacts and will therefore be the focus of this essay.

Technique is defined by the Oxford Dictionary as "a method of accomplishing a desired aim." This definition is sufficiently broad for my purposes and so I will keep using the term "technique." Importantly, the word "method" suggests that techniques are structured and ordered, but most importantly it suggests that techniques, too, are the result of human agency. Like artifacts, techniques are developed "for something," they are human made. In this sense, both artifacts and techniques are artificial (i.e., human-made), but only artifacts are artifactual in that they are material objects. Ontologically, techniques are dispositional, they only come into being when they are needed, whereas artifacts typically continue to exist for a certain period after they are made. Their functions, however, may also be dispositional, only coming into being when they are used.

I identify four kinds of techniques: (a) motor, (b) perceptual, (c) cognitive, and (d) affective techniques. ${ }^{10}$ These techniques may overlap and intertwine, and mastery of such techniques often depends on learning and training. Motor techniques are ways of using or moving our body, drawing on our perceptual and neuromuscular systems. There are techniques for walking, running, swimming, whistling, speaking, and so on. Many, if not most, motor techniques concern how we interact with artifacts. For example, there are techniques for tying your shoelaces, making coffee, playing guitar, driving a car, writing with pen and paper, or using a computer mouse, calculator, remote control, smartphone, and so on. We need to activate our neuromuscular system as to interact successfully with the environment, including artifacts. Motor techniques are grounded in our body schema, which is a subpersonal representation of the body's size and location in space, feeding into action repertoires (Gallagher, 2006). Sensory information, mainly tactile, proprioceptive, and visual, allows the mind to create a three-dimensional model of the body's size and location, which is the basis for our fine-grained interactions with the environment.

Perceptual techniques are ways of interpreting perceptual information, which can be visual, auditory, olfactory, gustatory, tactile, and proprioceptive. ${ }^{11}$ A neuroscientist sees more information in a magnetic resonance imaging scan than a novice. A sound technician hears more information in sound recordings than a novice. ${ }^{12}$ A perfumer can smell more information in scents than a novice. A wine connoisseur can taste more information in flavors than a novice. A blind person can feel more information in braille than a novice. And a martial artist can sense its bodily motions and body's position in space with more sensitivity than a novice. Such perceptual techniques are often developed with training, typically through social learning and trial and error. So, the way the embodied mind extracts meaningful information from raw perceptual input can be trained and optimized.

Cognitive techniques are ways to perform a cognitive task, involving cognitive processes like remembering, calculating, navigating, or reasoning. This can be done by merely using our biological onboard cognitive system. For example, to remember the order of the planets in our solar system (Mercury, Venus, Earth, Mars, Jupiter, Saturn, Uranus, Neptune), we can memorize the mnemonic "My very educated mother just served us noodles." Cognitive tasks can also be done by using artifacts. For example, I can Google the question: "What is the 
order of the planets in our solar system?" and the answer will appear on my screen. Cognitive techniques may involve embodied and perceptual techniques. In order to perform some cognitive task, we often need to interact with and perceive artifacts. Cognitive tasks are essentially problem-solving activities, which are many and varied: putting together a piece of Ikea furniture, diagnosing a disease, preparing a lecture, navigating from a to b, remembering which groceries to buy at the supermarket, and so on. Motor, perceptual, and cognitive systems all work together to perform such cognitive tasks.

Affective techniques are ways to achieve, induce, or manage one's affective states. This can be done by merely using our biological onboard cognitive system. For example, some actors have developed techniques for "stage crying" by remembering an emotionally salient experience such as grieving or being in pain, in that way inducing affective states resulting in crying. Another example of an affective technique are mindfulness practices and breathing exercises, which can be used to manage one's stress levels. Affective states can also be achieved by interacting with artifacts. For instance, creative artifacts such as films, songs, paintings, sculptures, installation art, and so on, can induce affective states (e.g., pleasure, confusion, surprise) when perceiving them. Personal artifacts like mementos, souvenirs, and photos can also induce affective states. Browsing through an old photo album may induce nostalgia, amusement, regret, or embarrassment. Motor, perceptual, cognitive, and affective systems all work together to perform such tasks and induce such affective states.

Finally, our learning capabilities suggest that the embodied agent that interfaces with the artifactual world is not a static creature but constantly changes over time. Underpinned by the brain's neural plasticity, we learn new interactive techniques allowing us to interact with artifacts in novel ways (Heersmink \& Knight 2018). Body schemas adapt to new artifacts and artifactual environments, perceptual systems learn to interpret the (artifactual) world in new ways, cognitive systems learn how to solve problems and achieve goals in news ways, and affective systems respond differently to (artifactual) stimuli over time. The embodied agent is thus a malleable agent, constantly adapting to its environment to skillfully optimize the fit between agent and artifact, implying that the relations we have to artifacts are renegotiated and change over time. The use of artifacts can be conceptualized along a spectrum of expertise. The first time we use an artifact, it requires a lot of conscious, cognitive effort, but over time, we become better at using an artifact and its use becomes more proceduralized. Also, artifacts may relate to different subjects in situated ways but with historicity informing the situation. Different agents bring different techniques to the situation and these influence the sorts of relations we have to an artifact.

\section{Embodied artifacts}

Having defined some of my key terms and identified a number of techniques, I now continue to describe four categories of artifacts, starting with embodied artifacts.

Some artifacts perform their function only when we bodily interact with them, and their successful use depends on specific motor and perceptual techniques. Hammers, screwdrivers, 
pens, paint brushes, cutlery, chop sticks, cricket bats, and other handheld devices perform their function only when we hold them and apply pressure or force to the artifact. ${ }^{13}$ Perceptionaction coupling facilitates the successful use of such artifacts. ${ }^{14}$ Phenomenologically, such artifacts can feel like transparent extensions of our body. This phenomenon was first conceptualized by Martin Heidegger (1962) in his classic work, Being and Time. He argues that we do not so much interact with the artifact but more so with the external world through the artifact. When hammering, writing, painting, or eating, we do not focus on the artifacts themselves but on how to use them to engage in the activity and perform a task. In such cases, the focus of the agent is not on the agent-artifact interface but on the artifact-environment interface. Heidegger refers to such artifacts as "equipment." Another classic example from the history of phenomenology is Merleau-Ponty's (1965) blind person using a cane. For the blind person, the cane feels like an extension of the body, allowing the person to sense the world.

A characterizing feature of embodied artifacts is transparency ${ }^{15}$. Transparency can be seen as a spectrum. The first time a user picks up a hammer, the hammer is difficult to use, but over time, the user gets more fluent in using it. We have to learn to embody the artifact. Transparency is a function of expertise and happens because artifacts are absorbed in the body schema. To accommodate a growing and changing body, the way the mind represents the body's size and location in space is flexible and can be updated. This flexibility also allows nonbiological objects, including artifacts, to be incorporated into the body schema (Schettler, Raja, \& Anderson, 2019). Body schemas can be recalibrated as to adjust to the material properties of the artifacts (such as its size, weight, and weight distribution) and take these properties into account when using it to achieve some goal.

Some artifacts need our motor input, in the sense that we need to push a button, flip a switch, pull a lever, or turn a knob. Keyboards, touchscreens, light switches, door handles, and so on require our bodily interactions. We may interact with these artifacts in a more or less transparent way, in that we do not need to think much about how to interact with these artifacts. A skilled keyboard user, for example, can use a keyboard without looking at it and without thinking much about how to use it. However, these artifacts are not embodied, in that they are not incorporated into the body schema and are not experienced as extensions of the body.

We have an intuitive sense of where our body is in space and artifacts can extend this sense of embodiment. Interestingly, we also have an intuitive sense of where some artifacts are located in space. For example, when we walk through our house in dim light, we can oftenwithout thinking much about it—navigate from one room to another without bumping into artifacts like chairs and tables. We are so familiar with the layout of our house and the artifacts in it that the environment is navigationally transparent to us. In a sense, this is the opposite of an embodied artifact, because we transparently know how to avoid interacting with artifacts. This transparency is grounded in both our body schema and cognitive maps. A cognitive map is an internal representation of our environment (Epstein, Patai, Julian, \& Spiers, 2017). These maps are generated by integrating different kinds of perceptual information, including visual, auditory, and tactile, to create and store a spatial map of one's environment. If one knows where one is, it is possible to create a vector within a cognitive map, allowing one to navigate through an environment such as a house or a more complex environment like a 
city. Blind people have particularly well-developed cognitive maps and can navigate complex environments like cities by merely relying on their cane and their hearing and smell. Our body schema allows us to know the size and shape of our body and its position in space, and our cognitive maps allow us to know the layout of our house and the artifacts in it. Integrating information from body schemas and cognitive maps allows us to, in some cases, transparently navigate our environment like our house, even in challenging situations such as when it is dimly lit. I refer to this phenomenon as "environmental transparency."

\section{Perceptual artifacts}

Perceptual artifacts are used to help us perceive or quantify the world better. They do so by correcting or amplifying our sensory capacities or by making visible and quantifying aspects of our world. Some artifacts correct deficiencies in the physiology of our perceptual apparatus. Glasses, for example, allow the eye to focus light in the right spot on the retina. Likewise, hearing aids detect and amplify sounds such that an underdeveloped, weakened, or damaged eardrum can still detect sounds. Glasses and hearing aids are used to correct physiological deficiencies to achieve a desired perceptual capability. Artifacts can also enhance nondeficient physiological capacities of our perceptual apparatus. Binoculars, microscopes, and telescopes magnify the amount of light detected by the retina, allowing a user to see things in the environment that would otherwise be invisible. Human visual systems are not able to peer into the microscopic and macroscopic without artifactual aid. Stethoscopes, likewise, amplify sound, allowing a user to hear more than would otherwise be possible. ${ }^{16}$

A particularly interesting kind of perceptual artifact are sensory substitution devices. These are devices that substitute the characteristics of one sensory modality (e.g., vision) into stimuli for another sensory modality (e.g., tactility) (Bach-y-Rita \& Kerel 2003). A sensory substitution system consists of three parts: a sensor, a coupling system, and a stimulator. The sensor (e.g., a camera mounted on a pair of glasses) detects environmental stimuli and a coupling system translates these into stimuli for another modality (e.g., tactility), which are generated by a stimulator (e.g., an array of electrodes placed on the skin that can vibrate). Visual information is thus translated into tactile information. After extensive training, participants can "see" objects in their environment through feeling the vibrations created by the electrode array. While sensory substitution devices remain largely experimental, they show what it possible in terms of the interaction and integration between artifacts and sensory systems, facilitated by the brain's plasticity.

Imaging devices like ultrasound, MRI, night vision goggles, radar systems, and infrared satellites, allow us to make visible and quantify aspects of our world. They require perceptual techniques to meaningfully interpret their informational content. Many professional, engineering, and scientific activities are performed with imaging devices. We interact bodily with some of these devices such as ultrasound technology, whereas others perform their function more or less independently of the human body such as radar systems. The function of imaging devices is to create an external representation, either fixed or in real-time, that allows us to indirectly perceive some aspect of the world that we would not otherwise be able to 
perceive such as brain structures, organs, and the location of objects beyond our visual reach. The cognitive, cultural, and scientific importance of such artifacts can hardly be overstated. Visualizing, quantifying, and mapping our world puts us in a better position to understand and control it, creating enormous progress for virtually all fields in engineering, science, and trade. It is safe to say that measurement and imaging technology create significant progress for the human species.

\section{Cognitive artifacts}

Cognitive artifacts are human-made, material objects or structures that functionally contribute to performing a cognitive task (Heersmink, 2013a, 2016; compare Vaccari, 2016). Examples of cognitive artifacts include maps, labels, abacuses, diaries, indexes, search engines, diagrams, models, computer systems, and leaving a rented DVD on your desk as a reminder to bring it back to the video store. Successfully using such artifacts typically requires a combination of motor, perceptual, and cognitive techniques. Most research in the situated and 4E cognition literature has focused on cognitive artifacts. Research on such artifacts obtained prominence in the 1990s with the work of Norman (1991, 1993), Hutchins (1995, 1999), Kirsh (1995), Kirsh and Maglio (1994), and others at the Department of Cognitive Science at the University of San Diego. ${ }^{17}$ Norman (1993) argues that these are the "things that make us smart" and without them our cognitive capacities would be radically different. Using cognitive artifacts often enhances our cognitive capacities, making cognitive tasks easier, faster, more reliable, or possible at all.

Heersmink (2013a) develops a taxonomy of cognitive artifacts, identifying various categories based on the informational properties of the artifact. ${ }^{18} \mathrm{He}$ starts by distinguishing representational and nonrepresentational cognitive artifacts. Representational cognitive artifacts contain information that refers to something else. Charles Saunders Peirce argues that a representational system involves a triadic relation between an interpretant (an understanding of the sign's object), sign (representation or representational vehicle), and object (represented world or target domain) (see also Fasoli, 2018b; Haugeland, 1991).

Peirce's $(1935 \mathrm{a}, \mathrm{b})$ trichotomy of icons, indices, and symbols is helpful to further distinguish kinds of representations (see also Atkin, 2008). An icon is structurally similar to its target domain. Maps, scale models, and an architect's blueprint are key examples, where the representational structure of the icon resembles the structure of the target domain. An index has a direct causal connection between index and target domain. Thermometers, scales, radar systems, and many other measuring devices are key examples, where temperature, weight, and the location of objects are directly connected (in real-time) to the representational state of the index. If the temperature would drop, it would be immediately visible on the index. Symbols, finally, neither resemble their target domain nor have a direct causal connection to the target but obtain their representational properties through social agreement and logical rules. Language, number systems, and mathematical symbols are key examples. The structure of letters, words, sentences, numbers, and mathematical symbols (such as for example the symbol for Pi: $\pi$ ) is largely arbitrary and, in most cases, a matter of convention and social 
agreement. The meaning of words, sentences, numbers, and most other symbols comes about through implicit agreement between a group of people.

Nonrepresentational cognitive artifacts do not have a target domain to which they refer. For example, when I consistently leave my car keys on the same spot in my house or leave a rented DVD on my desk as a prompt to bring it back to the video store, I use the location of those artifacts as a memory aid. By putting these artifacts in certain locations that are either deliberately usual or deliberately unusual, I intentionally encode information into the artifact and its location. Heersmink (2013a) has referred to such artifacts as "ecological cognitive artifacts." These aid us in performing cognitive tasks such as remembering, but not by having representational properties in the Peircean sense. Rather, these are characterized not by exhibiting information about the world, but as the world and thus exhibit nonrepresentational or ecological information.

The kinds of cognitive artifacts we use to perform a task has downstream effects on our cognition. For example, whether one makes notes with pen and paper or with a laptop has consequences for memory and understanding. In their empirical research, Mueller and Oppenheimer (2014) showed that laptop notetakers tend to transcribe lectures verbatim, rather than processing information and reframing it in their own words, which is detrimental to learning and memory. So, because taking notes with pen and paper is a slower process than taking notes on a computer, it means we have to think through the material we want to write down and only write down the most important parts, which has a positive effect on our level of understanding and memory.

Some cognitive artifacts are used to learn a cognitive technique. An abacus, for example, is used to learn mathematical skills, but once those skills are learned, we no longer need the abacus to perform calculations. In this case, the artifact temporarily supports the development of a cognitive capacity. Other cognitive artifacts are more permanent. Digital calendars, for example, are used for long periods of time and do not support the development of a cognitive capacity, but merely help us to remember our appointments. So, some cognitive artifacts are temporary supports, whereas others are more permanent supports. ${ }^{19}$

A specific type of cognitive artifact, with a more autobiographical function, are referred to as "evocative objects"20 (Heersmink 2018, 2020a; Turkle 2007). Cognitive artifacts are used to perform a practical problem-solving task like navigating, calculating, or planning. Evocative objects - by contrast - are used to remember our personal past. Examples include photos, videos, souvenirs, postcards, concert tickets, journals, books, works of art, trophies, inherited objects, and many other mementos. When we interact with such objects, the content of stored personal memories is retrieved into consciousness. In this sense, an evocative object is still a cognitive artifact, in that it contributes to cognitive processes. However, because autobiographical remembering is a distinct type of cognitive process, objects contributing to this process have an existential and sometimes affective dimension that is lacking in regular cognitive artifacts and, for this reason, deserve a special label. Evocative objects can have representational and nonrepresentational properties. A childhood photo reminding you of a past holiday does so through exhibiting iconic properties, whereas a suitcase reminding you of a previous trip is not representational in the Peircean sense. Such objects often obtain their 
autobiographical meaning through individually attributing meaning to the object, in which case we learned to associate the object with a memory.

There is currently an increasing use in lifelogging technology, where artifacts are used to capture and store the personal past (Bell \& Gemmell 2009). A prominent lifelogging artifact is a SenseCam, a small wearable camera worn around the neck with a lanyard with a wideangle lens that takes a picture every time its internal sensors detect a change in GPS location or light intensity (Hodges et al. 2006). Information collected by wearable cameras, GPS tracking devices, Fitbits, and other sensors is put in a database referred to as a "lifelog." This lifelog functions as an external autobiographical memory. This technology is used by cognitively healthy people to provide them with more detailed information about their past experiences, but also by people with memory impairments such as amnesia, brain injury or dementia to help such patients cope with their memory loss (Crete-Nishihata et al., 2012).

\section{Affective artifacts}

Emotion is traditionally conceptualized as a purely internal and biological affair. Most emotion theorists and psychologists focus on emotion as instantiated in the biological body. However, Paul Griffiths and Andrea Scarantino recently pointed out that "Emotion is a form of skillful engagement with the social environment that involves a dynamic process of negotiation mediated by reciprocal feedback between emoter and interactants" (2009, p. 443). Griffiths and Scarantino focus on emotional aspects of social interactions, but interactions with artifacts also have an emotional and affective component. ${ }^{21}$

Colombetti and Roberts (2015) outline the landscape of affectivity, which includes emotions, moods, sentiments, temperaments, and character traits. Paradigm emotions include fear, anger, sadness, hope, shame, joy, and contempt. Examples of moods are having the blues, being grumpy, and feeling anxious. Sentiments are tendencies to feel a variety of different emotions. Temperaments are tendencies to have certain moods such as being cheerful, being prickly, and being melancholic. Character traits are dispositions to evaluate and affectively respond to experiences and events in a certain way. We can, for example, be optimistic, friendly, loyal, modest, cruel, and courteous. Affective states, processes, and dispositions may sometimes be grouped into more than one of those categories. These categories are neither meant to be exhaustive nor mutually exclusive, but they do give an elaborate overview of the affective landscape.

The way affective states, processes, and capacities interact with material artifacts has recently been put center stage in the situated and $4 \mathrm{E}$ cognition literature (Carava \& Scorolli 2020; Carter, Gordon, \& Palermos, 2016; Colombetti, 2020; Colombetti \& Krueger 2015; Colombetti \& Roberts 2015; Krueger \& Szanto 2016; Piredda, 2020; Saarinen, 2020; Slaby, 2014; Viola, 2021). These theorists point out that emotion and affect are strongly influenced by material artifacts. It is, of course, commonplace to recognize that things in our environment can cause certain emotions. Dangerous animals make us fearful and traffic jams make us angry and frustrated. Artifacts, too, can be used to induce certain affective states. These are 
of particular interest because we have more intentional control over them and, for that reason, can be used as a form of emotion management.

Giulia Piredda defines affective artifacts as "as material or non-material objects that have the capacity to alter the affective condition of the agent" (2020, p. 550). Some artifacts are deliberately made and used for affective purposes. Creative artifacts such as paintings, sculptures, music, cinema, and installation art are made and used to induce affective and cognitive states in the viewer or listener. Likewise, musical instruments are made to make music, thereby expressing one's emotions and moods. Collections of artifacts such as stamps, old cameras, or antiques are affectively meaningful for the collector. Successfully using affective artifacts typically requires a combination of motor, perceptual, cognitive, and affective techniques. Colombetti, Krueger, and Roberts (2018) point out that "we regulate, organize, and maintain our affective life by manipulating everyday artifacts and spaces. We make and listen to music, adorn walls with artworks, consume drugs, wear specific clothing, and gravitate toward spaces and social groups to evoke and regulate different affective experiences" (p. 1). So, importantly, it is not just singular artifacts that make us feel a certain way; spaces, too, have an effect on the way we feel. When coming home after a long day at work, for example, one may feel comfort and safety. It is not a specific artifact in one's home that causes this state, but the entire space and the artifacts in it. The paradigm cases of affective artifacts are those that an agent has some intentional control over. Some artifacts, however, are not deliberately made and used for affective purposes, but can still alter the affective state of an agent in an unintentional manner.

\section{Blurring the boundaries}

Up to now, I have discussed these kinds of artifacts as separate categories, which is conceptually helpful in identifying their unique functional properties. However, these categories can overlap (Figure 1). In this section, I briefly discuss some examples of artifacts with functional properties that can be grouped in more than one category. Embodied and perceptual artifacts sometimes coincide. A blind person using a cane, for example, perceives the world by using an embodied artifact. The cane is absorbed in the body schema, experienced as a transparent extension of the body, and used to sense objects in the environment.

It is less common for embodied and cognitive artifacts to coincide, but I will discuss one example at the end of this section. It is more common to use embodied artifacts to interact with cognitive artifacts. We use a computer mouse to interact with a computer. The mouse can be seen as an embodied artifact, as it is absorbed in the body schema and experienced as a transparent extension of the motor system, but it is not a cognitive artifact. The same is true for a stylus we use to interact with touchscreens. Embodied and affective artifacts can overlap, too. Musical instruments are typically transparent in use, in that the experienced musician does not have to think much about how to use the instrument to create the music he or she wants. One can think of musical instruments as affective artifacts for acting both on the world and on oneself, that is, their function is to induce affective states in the musician and listeners. ${ }^{22}$ 


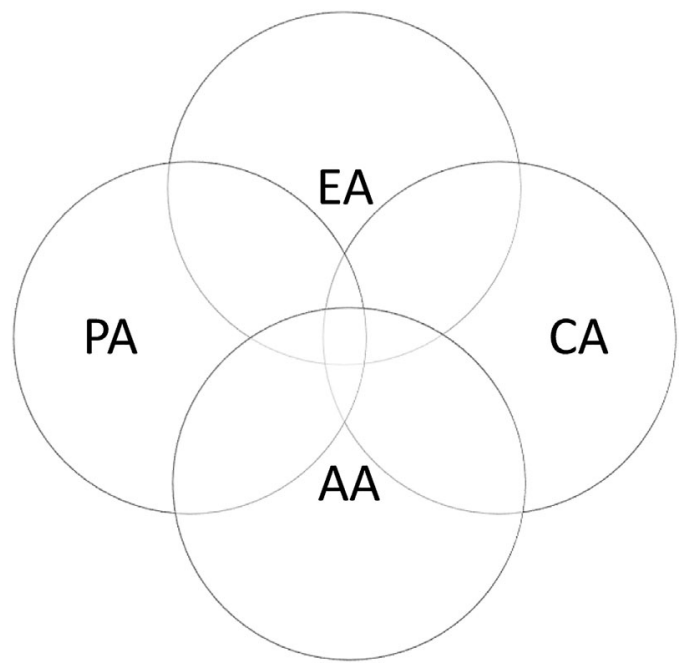

Fig. 1. A Venn diagram of the relations between embodied artifacts (EA), perceptual artifacts (PA), cognitive artifacts (CA), and affective artifacts (AA), showing that these categories can overlap.

Perceptual and cognitive artifacts also often overlap. Many measuring devices provide their user with an external representation that is used in performing a cognitive task. A radar system, for example, creates an external representation of the location of objects, which is used to navigate. Also, a wine tasting wheel contains information about the relation between different flavors and aromas in wine. It is a cognitive artifact guiding and enhancing our olfactory and gustatory interpretation of wine. Perceptual and affective artifacts overlap, too. A bird watcher my feel fond of his binoculars, or the complexity and inner workings of a microscope may create a feeling of being intrigued in a scientist.

Cognitive and affective artifacts can coexist in one artifact, which happens specifically in evocative objects. For example, when looking at a photo of one's $\mathrm{PhD}$ graduation ceremony, it may evoke a variety of personal memories about the event. Given the emotional significance of the event, it may also induce affective states like nostalgia or pride. With such personal memories it is possible that the informational component and the affective component are interwoven. So, when the memory is retrieved, it causes us to feel a certain way. In this sense, an artifact can both be evocative and affective.

The ill-fated Google Glass can be embodied, perceptual, cognitive, and affective in nature. Embodied, because it is a transparent extension used to perceive the world. Perceptual, because it corrects deficiencies in the physiology of the visual system. Cognitive, because it presents its user with external representations like reminders or overlaid directions used to perform cognitive tasks. Affective, because it allows the user to view photos of past experiences, triggering memories may have an affective component. Google Glass is now almost a decade old and perhaps not the most efficient artifact, but it is not hard to image future wearable computing devices that are more transparent, computationally powerful, and multifunctional, and are deeper integrated into our embodied, perceptual, cognitive, and affective 
systems. So, what makes an artifact embodied, perceptual, cognitive, or affective is the relation it has with the user, and more than one type of relation can occur between an embodied agent and a specific artifact. We can identify parts of the landscape of relations between humans and artifacts, and by doing so characterize the unique properties of that part of the landscape, but these parts are porous and bleed into each other. ${ }^{23}$

Finally, we sometimes use an artifact together with other embodied agents. For example, tandems, see-saws, roundabouts, family-size hammocks, citizen science platforms, and multiplayer videogames are artifacts where their proper use depends on more than one user. We must then negotiate and collaborate with one or more agents to perform the task. In such cases, we can distinguish between knowledge needed to do the work (tasks, artifacts, and techniques), knowledge of your partner's skills (keeping the focus on dyads as complexity explodes with $>2$ ), and expectations for how you and your partner will coordinate your separate and your common activities. Some of such artifacts can be embodied, for example in case of a tandem or see-saw, when used for a significant period of time, they can become transparent in use, and possibly feel like an extension of one's body. But the way the artifact is embodied depends on one's co-user. Citizen science platforms and multiplayer videogames involve the use of external representations and are more cognitive nature. In these cases, the actions of others influence how one interacts with the digital system and performs the tasks. Affective artifacts, too, are sometimes used in collaboration with others. When playing guitar in a band, for example, what you play must be in tonal and rhythmic harmony with what your fellow musicians play.

\section{Current trends}

In this final section, I outline a number of recent trends regarding the design and use of embodied, perceptual, cognitive, and affective artifacts, focusing on neuroprosthetics, braincomputer interfaces, and personalization algorithms.

\subsection{Neuroprosthetics}

Neuroprosthetics is a field combining neuroscience and biomedical engineering as to develop neural prostheses. Such prostheses aim to partly restore vision, audition, and motor functions by interfacing with the nervous system. For instance, biomedical engineers from MIT's Media Lab developed an agonist-antagonist myoneural interface, allowing a connection between muscles in the residuum of an amputee with a bionic leg (Srinivasan, Diaz, Carty $\&$ Herr 2019). The mechanics of the bioartifactual system work as follows: An agonist and an antagonist muscle in the amputee's residuum are surgically connected such that contraction of one muscle stretches the other. The dynamics between the agonist-antagonist muscles allow proprioceptive signals from mechanoreceptors within both muscles to be communicated to the central nervous system. Electrodes on the muscles detect signals which are processed by a small computer embedded in the system and used to control the bionic limb. This type of neuroprosthetics is interesting because it allows the amputee to both use the limb and to 
proprioceptively feel it. This feedback allows it to be absorbed in the body schema. In a TED talk, the first patient to receive such a myoneural interface reports that:

I didn't feel like a cyborg. I felt like I had my leg, and it wasn't like I felt I was attached to the robot so much as the robot was attached to me. The robot became part of me. It became my leg pretty quickly (Herr, 2019).

This suggests that the artifact becomes transparent to a large degree, is experienced as part of the embodied agent, and becomes part of the machinery with which the agent encounters the world (Heersmink, 2020b).

Brain-computer interfaces (BCIs) are a type of neuroprosthetics. Electrodes, either invasive or noninvasive, detect brain activity that is translated into command signals for an external device such as a cursor on a computer screen, robotic hand, wheelchair, or other device. A $\mathrm{BCI}$ bypasses the peripheral nervous system, thereby providing a means of communication for people suffering from severe motor disabilities. BCIs can also be used by agents who do not have motor disabilities. They provide a unique way of acting on the world: an embodied agent can act on the world and realize his or her intentions merely by thinking certain thoughts (often imaging certain movements). Early BCI systems where difficult to use and where not (fully) transparent (Heersmink, 2013b), but significant progress has been made and BCIs are now easier to use (Yadav, Yadav, \& Veer, 2020).

Neuroprosthetics can also partly restore perceptual systems. A visual neuroprosthesis can create a sense of vision by electrically stimulating neurons in the optical nerve by means of an implanted electrode array. Currently, these devices are only able to restore a very limited vision, with relatively low spatial resolution (Fernandez, 2018). Similarly, cochlear implants directly stimulate the auditory nerve through an implanted electrode array. Glasses and hearing aids can be easily removed, but retinal and cochlear implants are a cyborg technology, in that they are physically connected and integrated into the human body and can only be removed through surgery. Retinal implants are still in an experimental stage, whereas cochlear implants are now commercially available.

A final example I mention here are deep-brain stimulation devices, which are implanted into the brain and stimulate parts of the brain that are specific for the disorder they are treating. These devices can be used to treat various medical conditions, including clinical depression and other mood disorders (Kisely, Li, Warren, \& Siskind, 2018). They can be used to influence one's mood and are thus a type of affective artifact. But rather than using external artifacts to induce or manage one's affective states, a deep-brain stimulation device bypasses the perceptual system altogether and directly stimulates parts of the brain associated with mood and affect.

These brief examples show there is significant progress being made in the field of neuroprosthetics, where artifacts are directly connected to the nervous system, allowing agents to act on the world, perceive the world, and regulate their affect in novel ways. At this stage, they are mainly developed for people with disorders, and are thus largely assistive technologies, but some (particularly BCIs) are also used by people who are not disabled. Whether such agents will choose to use neuroprosthetics to enhance how they act on the world, perceive the world, and regulate their affect remains to be seen (Teunisse, Youssef, \& Schmidt, 2019). 


\subsection{Personalization algorithms}

Information-storage and memory functions have been shifting outwards since the invention of artifacts such as clay tablets, papyrus scrolls, books, and libraries (Heersmink \& Sutton 2020). A more recent trend is that information-processing functions are now also performed by artifacts. Arguably, this started with analogue devices like the abacus and slide rulers, was amplified by the invention of the digital computer in the 1950s and is now significantly accelerating with the development of artificial intelligence (AI). I will now look at one specific application of AI, namely personalization algorithms ${ }^{24}$ and their effects on cognition and emotion.

In the last decade or so, our cognitive ecologies are increasingly constituted by AI algorithms (Burr, Cristianini, \& Ladyman, 2018; Smart, Clowes, \& Heersmink, 2017; Smart, Heersmink, \& Clowes, 2017; Zanker, Rook, \& Jannach, 2019). Cognitive ecologies can be defined as "the multidimensional contexts in which we remember, feel, think, sense, communicate, imagine, and act, often collaboratively, on the fly, and in rich ongoing interaction with our environments" (Tribble and Sutton 2011, p. 94; see also Hutchins, 2010). Algorithms on Google Search, YouTube, Facebook, Instagram, Spotify, Amazon, Academia, ResearchGate, and other webpages personalize one's feed, based on previous online behavior, which has significant effects on the kind of information one consumes (Mittelstadt, Allo, Taddeo, Wachter, \& Floridi, 2016). These algorithms can be hugely helpful, in that they streamline our interactions with the online world and point us to information we would have otherwise missed. But there are also drawbacks. These algorithms generate personalized epistemic choice architectures, sometimes nudging one toward an informational path that is not necessarily epistemically, cognitively, or affectively beneficial. Below I briefly discuss three algorithms that nudge one toward certain informational options or nudge one toward having certain affective states, namely Google Search's algorithm, YouTube's recommender algorithm, and the algorithms behind Facebook's News Feed.

Google Search provides its users with a filtered portal to the online world. Google stores one's previously used search terms and visited webpages, which results in a unique informational profile for each user. Based on that profile, an algorithm ranks webpages resulting in a search engine results page (Heersmink, 2018a). Webpages that are visited previously are prioritized over those that have not been visited and webpages that contain terms used previously are also prioritized. So, the algorithm leaves out some webpages and prioritizes others based on one's search and browsing history, resulting in "filter bubbles," potentially leading to biased views (Heersmink \& Sutton 2020; Miller \& Record, 2013; Nguyen, 2020; Simpson, 2012; but compare Smart \& Shadbolt 2018). This is undesirable as it may reinforce one's confirmation bias. Humans tend to more easily agree with new information that is consistent with their current views and tend to less easily agree with information that is inconsistent with their current views. Filter bubbles created by Google Search may amplify our confirmation biases, as it tends to present us with information consistent with our current worldview.

YouTube's recommender system personalizes the videos it suggests to the viewer. It shares recommendations on its homepage and in the "Up next" section as a suggestion of which videos to watch next when you are watching a video. The algorithm is optimized to promote clips that users are likely to watch through to the end. Seventy percent of all watch-time on 
YouTube is driven by its recommender system (Solsman, 2018), so it has a significant effect on what information viewers consume. A lot of variables feed into the algorithm, including your watch and search history on both YouTube and Google Search, the channels you are subscribed to, your geographical context like your country, and the time of day. This creates a real-time feedback loop that tailors videos to each viewer's different interests. While this can certainly be helpful and draw attention to interesting videos that would have otherwise remained unseen, it also has some unintended and undesirable consequences. Like with Google Search, it creates a "filter bubble" in which users are only exposed to information that fits in their current worldview. Commentators have pointed out that it is possible that this contributes to the (political) polarization that currently exist in most Western cultures. Some philosophers go further and point out that YouTube's "recommender system tends to recommend extremist content and conspiracy theories, as such videos are especially likely to capture and keep users' attention (Alfano, Fard, Carter, Clutton, \& Klein, 2020, p. 1). Over time, YouTube could contribute to self-radicalization, causing people to have extremist views on religious or political topics (Alfano, Carter, \& Cheong, 2018).

The above examples show that personalization algorithms can influence one's beliefs and other cognitive states. Personalization algorithms can also influence our emotions and affective states, and in this sense can be seen as affective artifacts. Consider the experiences of the following commentator quoted in Jose van Dijck (2013) who is reflecting on his experience with Facebook when its new timeline format was introduced in 2011. Prior to 2011, Facebook organized posts in a nonchronological manner.

Years-old memories flashed before me - old friends, old places, things I hadn't thought about in ages. I got sucked back into the past the same way I would have in front of my mother's old cedar chest, a trunk packed full of childhood tchotchkes and pictures that holds our family's history. This innocuous social web tool had just made a powerful and convincing bid for more than my information or my time. Facebook was grasping at my emotions by way of my memories, and it was doing a damn good job (van Dijck 2013, p. 205).

The experiences of this particular commentator suggest that one's Facebook profile is a repository of meaningful affectively laden autobiographical memories. By algorithmically organizing these in a chronological and narrative manner, algorithms tap into our emotions and affective states. Another example is Facebook's "On This Day" algorithm, which determines your most popular posts, based on likes and comments, and reminds you of the event each time a year has passed since posting it. Popular posts typically have a strong affective significance to the user and reminding users of such posts is part of Facebook's business model to keep their users interacting with Facebook.

It is, of course, no surprise that Facebook's algorithms have an impact on our emotions and affective states. In 2012, researchers conducted an emotional contagion study on more than 680,000 Facebook users (Kramer, Guillory, \& Hancock, 2014). They reduced the number of positive or negative posts shown to users by manipulating the algorithmically controlled "News Feed" and then studied the effects of this on their own posting behavior. They focused 
on verbal expressions of emotions and whether a post was positive or negative was determined by an algorithm. The experiment shows that "When positive expressions were reduced, people produced fewer positive posts and more negative posts; when negative expressions were reduced, the opposite pattern occurred" (Kramer et al., 2014, p. 8788). So, the emotional valence of posts one reads on Facebook's News Feed influences the emotional valence of one's own posts. While the measured effects were not large, they were statistically significant, and show that - unbeknownst to us-algorithms can influence our emotions and affective states, which may be problematic when it happens without our awareness and without our consent.

When personalization algorithms nontransparently nudge their users toward specific epistemic paths of information consumption, it can have undesirable consequences ${ }^{25}$. One possible solution to this problem is turning off personalization in the settings (which is possible in Google Search, to some extent in YouTube, but not in Facebook). Another solution is making algorithms more transparent, for example by providing a short explanation on the feed about how the results were ranked or why they were suggested. Or, even better, we need to design algorithms in a way that they do not feed into and amplify our cognitive biases, add to (political) polarization, and deliberately influence our emotions and affective states without our knowledge or consent (see also Hernandez-Orallo \& Vold 2019). While users have an epistemic responsibility to remain and improve their intellectual virtues (such as intellectual autonomy and carefulness), technology designers and companies have a social responsibility to design algorithms and artifacts such that they reduce possible undesirable effects on their users' cognitive and affective states and processes (Heersmink, 2018a).

Finally, human biological brains evolve relatively slowly, cultural evolution goes much quicker. Most cognitive progress is achieved primarily through developing more efficient and powerful artifacts. The co-evolutionary process between embodied minds and artifacts is, it seems to me, largely driven by artifacts. The artifactual and informational ecology in which our embodied minds develop has an enormous impact on the kinds of capabilities human embodied agents end up having. This is partly because of the cumulative nature of material culture. Once an artifact has been invented, we can keep improving it (Sterelny, 2003). Given the prominent role of artifacts in the development and evolution of human cognitive capacities, we need to be careful with the kinds of artifacts we develop. This is true for all artifacts but rings particularly true for AI and personalization algorithms. We need to design artifacts such that their effects on us and the world are consistent with our moral and cultural values.

\section{Conclusion}

This essay first developed a comprehensive overview and analysis of the various ways material artifacts relate to the embodied mind. Based on their functional properties, I identified four categories of artifacts: (a) embodied artifacts, (b) perceptual artifacts, (c) cognitive artifacts, and (d) affective artifacts. These categories can overlap and so some artifacts are members of more than one category. I also identified some of the techniques (or skills) we use when interacting with artifacts. Identifying these artifacts and techniques allows us to map 
and better understand the landscape of relations between embodied minds and the artifactual world, showing how humans use embodied, perceptual, cognitive, and affective artifacts to achieve their aims, complete their tasks, and regulate their emotions. This essay ended with outlining some current trends regarding the design and use of artifacts, focusing on neuroprosthetics, brain-computer interfaces, and personalization algorithms.

\section{Acknowledgments}

I would like to thank the four reviewers for their perceptive comments, which significantly improved this paper. I would also like to thank Wayne Gray for the invitation to write a paper for this special issue.

\section{Notes}

1 For example, it is one thing for a primate to modify and use a stick to get termites out of a mound, it is quite another thing for humans to use the principles of aerodynamics and quantum mechanics to build a network of satellites, allowing humans to navigate by using GPS devices, access the internet, and photograph the entire world. A reviewer pointed out that tool-using animals have to learn how to use tools, either through observing how other animals use tools (i.e., social learning) or through trial and error. This shows that some animals have sophisticated learning capabilities when it comes to tool-use. Particularly impressive are New Caledonian crows, who learn how to make tools from twigs through both trial and error and social learning (Holzhaider, Hunt, \& Gray, 2010). However, human tool-use differs from animal tool-use in a number of important ways (Vaesen, 2012).

2 A related but more general notion is that of "Homo faber," Latin for man the maker, which is the concept that humans are able to control their fate and their environment as a result of the use of tools and artifacts. This is a familiar theme in anthropology and philosophy, see e.g., Bergson (1911) and more recently Ihde and Malafouris (2019). Other theorists working on human-technology relations include Haraway (1991), Ihde (1990), and Latour (2005).

3 Clark (2003) does not talk about the way artifacts and affective systems are integrated.

4 Baber $(2003$, 2018) adopts a different approach to mapping the relations between embodied agents and their artifactual world, focusing on the Gibsonian notion of affordance. See Rietveld and Kiverstein (2014) for a similar Gibsonian approach.

5 Something can be an artifact without it ever being used. For example, an unused hammer ending up in landfill is still an artifact. So, being used is not a necessary condition for being an artifact. I will not be discussing unused artifacts in this essay.

6 Given the crucial role of material culture in human capabilities, it is no surprise that there are many words in the English language to refer to human-made material objects: tools, artifacts, technologies, apparatuses, instruments, devices, machines, and so on. Artifact, however, is the most general and is used most consistently in the philosophy of technology literature. 
7 Nonhuman animals sometimes use and make artifacts. Spiders, for example, create webs, beavers build dams, birds make nests, moles dig burrows, and termites build mounds. This kind of artifact-use allows nonhuman animals to actively alter their niche, creating a safer, more regulated, and functional environment (Laland, Odling-Smee, \& Feldman, 2000).

8 Improvised functions of artifacts have also been referred to as "system functions" (Preston, 2013). I have discussed the difference between proper and system function in more detail in Heersmink (2016), which also includes an analysis of the relation between the material structure of the artifact and its proper and system function.

9 This paper is about artifacts and their functional relations to their users. But it is important to acknowledge that motor, perceptual, cognitive, and affective tasks can also be performed with other people. We dance with other people, our passengers may help us perceive the environment and help us navigate, our partners may help us put together a piece of Ikea furniture, and reminiscing about the past with an old friend may cause us to feel a certain way.

10 By identifying these techniques, I do not want to suggest a neatly compartmentalizable ontology of mind. Motor capabilities, perception, cognition, and affect often bleed into each other and are mutually constitutive.

11 Hutchins (1995, p. 172) defines perceptual techniques as "internal artifacts." I prefer the term perceptual technique because biologically realized mental states and processes are not artifacts. This would be stretching the concept too far, in my view. They may perform the same function as an artifact but do not have the same ontological status and properties.

12 A particularly interesting example of perceptual techniques is echolocation in humans. Some humans have developed the capacity to detect objects in their environment by hearing echoes from those objects (Downey, 2016). This is done by actively making sounds, for example by tapping a cane, lightly stomping their foot, snapping their fingers, or making clicking noises with their mouths. Hearing the reflected sounds allows them to accurately identify the location and size of objects in the environment.

13 Given the definitions in Section 2, these artifacts may also be referred to as tools.

14 Gibson (1979) first pointed out that perception and action are coupled in a particular way.

15 For insightful discussions of transparency in relation to the extended mind see Wheeler (2019), Andrada (2020), Piredda and Di Francesco (2020), and Aagaard (2021).

16 One may ask whether a guide dog or a canary in a coal mine are perceptual artifacts. A canary in a coal mine seems closer to being a naturefact, a naturally occurring object or structure used for human purposes. A guide dog is trained and, in that sense, modified by humans and is therefore closer to being an artifact.

17 There have been other scholars working on cognitive artifacts such as Donald (1991). More broadly, for an overview of the scientific precursors of the situated cognition movement see Clancey (2008) and for philosophical precursors see Gallagher (2008).

18 For other taxonomies of cognitive artifacts, see Brey (2005), Nickerson (2005), Clowes (2013), John Sutton (2016), Casati (2017), and Fasoli (2018a). 
19 We can develop cognitive techniques by internalizing the informational properties of cognitive artifacts. A striking example are Japanese students who have learned to visualize the structure of an abacus and to internally manipulate the beads in mental imagery as to perform calculations (de Cruz, 2008). The material abacus is then no longer needed and is replaced by a "virtual" or "mental" abacus. The mental and material abacus have the same informational properties, but there may be differences in processing speeds.

20 I continue to use the phrase "evocative object" and not "evocative artifact," as that is how Sherry Turkle defined them in her 2008 edited book.

21 In this paper, I am neutral about what emotions and affects exactly are. There are various theories regarding emotions, including those that claim emotions are feelings, evaluations, or motivations (see Scarantino \& de Sousa, 2018 for an elaborate overview). I will be neutral about whether emotions are feelings, evaluations, motivations, or a combination of these. But at the very least, emotions are subjective states with a distinct phenomenology.

22 Or perhaps their function can be seen as being conduits between affective states of a musician and an audience.

23 Richard Sennett (2008) characterizes a boundary as an edge where one thing ends and another begins, while a border is a site of exchange. In terms of this distinction, the relations between embodied, perceptual, cognitive, and affective artifacts can best be characterized as a border.

24 Raymond Turner (2014) performs an interesting analysis of programming languages and algorithms as technical artifacts, conceptualising their structural and functional properties.

25 Online personalization can also be done by the agent, rather than an algorithm. For example, IMDB allows its users to rate films, thereby creating a personalized list of films. But this personalization is transparent and done by the agent, and, importantly, does not create filter bubbles and possibly reinforces one's confirmation bias, does not recommend extremist content and conspiracy theories, and does not influence our emotions and affective states without our knowledge or consent.

\section{References}

Aagaard, J. (2021). 4E cognition and the dogma of harmony. Philosophical Psychology, 34(2), 165-181.

Alfano, M., Carter, A., \& Cheong, M. (2018). Technological seduction and self-radicalisation. Journal of the American Philosophical Association, 4(3), 298-322.

Alfano, M., Fard, A., Carter, A., Clutton, P., \& Klein, C. (2020). Technologically scaffolded atypical cognition: The case of YouTube's recommender system. Synthese. https://doi.org/10.1007/s11229-020-02724-x

Andrada, G. (2020). Transparency and the phenomenology of extended cognition. Límite. Interdisciplinary Journal of Philosophy \& Psychology, 15(12), 1-17.

Atkin, A. (2008). Icon, index, and symbol. In P. Hogan (Ed.), The Cambridge encyclopaedia of language sciences (pp. 367-368). Cambridge, England: Cambridge University Press.

Aristotle. (1984). Nichomachean ethics, metaphysics, physics. In J. Barnes, (Ed.), The complete works of Aristotle, Volumes I and II. Princeton, NJ: Princeton University Press.

Baber, C. (2003). Cognition and tool use: Forms of engagement in human and animal use of tools. London, England: Taylor and Francis. 
Baber, C. (2018). Designing smart objects to support affording situations: Exploiting affordance through an understanding of forms of engagement. Frontiers in Psychology, 9, 292. https://doi.org/10.3389/fpsyg.2018.00292

Bach-y-Rita, P., \& Kerel, S. (2003). Sensory substitution and the human-machine interface. Trends in Cognitive Sciences, 7(12), 541-546.

Bell, G. M., \& Gemmell, J. (2009). Total recall: How the e-memory revolution will change everything. New York: Dutton.

Bergson, H. (1911). Creative evolution. Translated by Arthur Mitchell, New York: Dover.

Brey, P. (2005). The epistemology and ontology of human-computer interaction. Minds and Machines, 15(3-4), 383-398.

Burr, C., Cristianini, N., \& Ladyman, J. (2018). An analysis of the interaction between intelligent software agents and human users. Minds and Machines, 28(4), 735-774.

Carava, M., \& Scorolli, C. (2020). When affective relation weighs more than the mug handle: Investigating affective affordances. Frontiers in Psychology, 11, 1928. https://doi.org/10.3389/fpsyg.2020.01928

Carter, A., Gordon, E., \& Palermos, O. (2016). Extended emotion. Philosophical Psychology, 29(2), 198-217.

Casati, R. (2017). Two, then four modes of functioning of the mind: Towards a unification of "dual" theories of reasoning and theories of cognitive artifacts. In J. Zacks \& H. Taylor (Eds.), Representations in mind and world (pp. 7-23). New York: Routledge.

Colombetti, G. (2020). Emoting the situated mind: A taxonomy of affective material scaffolds. JOLMA. The Journal for the Philosophy of Language, Mind and the Arts, 1(2), 215-236.

Colombetti, G., \& Roberts, T. (2015). Extending the extended mind: The case for extended affectivity. Philosophical Studies, 172(5), 1243-1263.

Colombetti, G., \& Krueger, J. (2015). Scaffoldings of the affective mind. Philosophical Psychology, 28, 11571176.

Colombetti, G., Krueger, J., \& Roberts, T. (2018). Editorial: Affectivity beyond the skin. Frontiers in Psychology, 9, 1307. https://doi.org/10.3389/fpsyg.2018.01307/full

Clark, A. (2003). Natural born cyborgs: Minds, technologies, and the future of human intelligence. Oxford, England: Oxford University Press.

Clark, A. (2008). Supersizing the mind: Embodiment, action, and cognitive extension. Oxford, England: Oxford University Press.

Clark, A., \& Chalmers, D. (1998). The extended mind. Analysis, 58(1), 10-23.

Clancey, W. (2008). Scientific antecedents of situated cognition. In P. Robbins \& M. Aydede (Eds.), The Cambridge handbook of situated cognition (pp. 11-34). Cambridge, England: Cambridge University Press.

Clowes, R. (2013). The cognitive integration of e-memory. Review of Philosophy \& Psychology, 4(1), 107-133.

Crete-Nishihata, M., Baecker, R., Massimi, M., Ptak, D., Campigotto, R., Kaufman, L. D., Brickman, A. M., Turner, G. R., Steinerman, J. R., \& Black, S. E. (2012). Reconstructing the past: Personal memory technologies are not just personal and not just for. Human-Computer Interaction, 27(1-2), 92-123.

De Cruz, H. (2008). An extended mind perspective on natural number representation. Philosophical Psychology, 21(4), 475-490.

Donald, M. (1991). The origins of the modern mind: Three stages in the evolution of culture and cognition. Boston, MA: Harvard University Press.

Downey, G. (2016). Sensory enculturation and neuroanthropology: The case of human echolocation. In J. Chiao, S. Li, R. Seligman, \& R. Turner (Eds.), The Oxford handbook of cultural neuroscience (pp. 41-55). Oxford, England: Oxford University Press.

Epstein, R. A., Patai, E. Z., Julian, J., \& Spiers, H. (2017). The cognitive map in humans: Spatial navigation and beyond. Nature Neuroscience, 20(11), 1504-1513.

Fasoli, M. (2018a). Substitutive, complementary, and constitutive cognitive artifacts: Developing an interactioncentered approach. Review of Philosophy and Psychology, 9(3), 671-687.

Fasoli, M. (2018b). Super artifacts: Personal devices as intrinsically multifunctional, meta-representational artifacts with a highly variable structure. Minds \& Machines, 28, 589-604.

Fernandez, E. (2018). Development of visual neuroprostheses: Trends and challenges. Bioelectronic Medicine, $4(12), 1-8$. 
Finley, J. R., Naaz, F., \& Goh, F. W. (2018). Memory and technology: How we use information in the brain and the world. Dordrecht, The Netherlands: Springer.

Gallagher, S. (2006). How the body shapes the mind. Oxford, England: Oxford University Press.

Gallagher, S. (2008). Philosophical antecedents of situated cognition. In P. Robbins \& M. Aydede (Eds.), The Cambridge handbook of situated cognition (pp. 35-51). Cambridge, England: Cambridge University Press.

Gibson, J. (1979). The ecological approach to visual perception. Boston, MA: Houghton Mifflin.

Griffiths, P., \& Scarantino, A. (2009). Emotions in the wild: The situated perspective on emotions. In P. Robbins \& M. Aydede (Eds.), The Cambridge handbook of situated cognition (pp. 437-453). Cambridge: Cambridge University Press.

Haraway, D. (1991). A cyborg manifesto: Science, technology and socialist feminism in the late twentieth century. In D. Haraway (Ed.), Simians, cyborgs and women: The reinvention of nature (pp. 149-181). London, England: Free Association Books.

Haugeland, J. (1991). Representational genera. In W. Ramsey, S. Stich, \& D. Rumelhart (Eds.), Philosophy and connectionist theory (pp. 61-89). London, England: Lawrence Erlbaum Associates.

Heersmink, R. (2013a). A taxonomy of cognitive artifacts: Function, information, and categories. Review of Philosophy and Psychology, 4(3), 465-481.

Heersmink, R. (2013b). Embodied tools, cognitive tools and brain-computer interfaces. Neuroethics, 6(1), 207219.

Heersmink, R. (2016). The metaphysics of cognitive artefacts. Philosophical Explorations, 19(1), 78-93.

Heersmink, R. (2018a). A virtue epistemology of the Internet: Search engines, intellectual virtues and education. Social Epistemology, 32(1), 1-12.

Heersmink, R. (2018b). The narrative self, distributed memory, and evocative objects. Philosophical Studies, 175(8), 1829-1849.

Heersmink, R. (2020a). Extended mind and artifactual autobiographical memory. Mind \& Language. https://doi. org/10.1111/mila.12353

Heersmink, R. (2020b). Varieties of the extended self. Consciousness \& Cognition, 85, 103001.

Heersmink, R., \& Knight, S. (2018). Distributed learning: Educating and assessing extended minds. Philosophical Psychology, 31(6), 969-990.

Heersmink, R., \& Sutton, J. (2020). Cognition and the Web: Extended, transactive, or scaffolded? Erkenntnis, 85(1), 139-164.

Heidegger, M. (1962). Being and time. London, England: SCM.

Hernandez-Orallo, J., \& Vold, K. (2019). AI extenders: The ethical and societal implications of humans cognitively extended by AI. Proceedings of the 2019 AAAI/ACM conference on AI, ethics, and society ( 507-513). https: //doi.org/10.1145/3306618.3314238

Herr, H. (2019). How we become cyborgs and extend human potential. [Video file]. Available from https://www. ted.com/talks/hugh_herr_how_we_ll_become_cyborgs_and_extend_human_potential?language=en\#t-628298

Hilpinen, R. (2011). Artifact. In E. Zalta (Ed.), Stanford encyclopedia of philosophy. https://plato.stanford.edu/ entries/artifact/

Hipolito, I., Clowes, R., \& Gartner, K. (Eds.) (2021). The mind-technology problem: Investigating minds, selves and 21 st century artefacts. Dordrecht, The Netherlands: Springer.

Hodges, S., Williams, L., Berry, E., Izadi, S., Srinivasan, J., Butler, A., Smyth, G., Kapur, N., \& Wood, K. (2006). SenseCam: A retrospective memory aid. In P. Dourish \& A. Friday (Eds.), Ubicomp 2006: Ubiquitous computing (pp. 177-193). Berlin, Germany: Springer.

Holzhaider, J. C., Hunt, G. R., \& Gray, R. D. (2010). Social learning in new Caledonian crows. Learning \& Behavior, 38(3), 206-219.

Houkes, W., \& Vermaas, P. (2010). Technical functions: On the use and design of artefacts. Dordrecht, The Netherlands: Springer.

Hutchins, E. (1995). Cognition in the wild. Cambridge, MA: MIT Press.

Hutchins, E. (1999). Cognitive artifacts. In R. Wilson \& F. Keil (Eds.), The MIT encyclopaedia of the cognitive sciences (pp. 126-128). Cambridge, MA: MIT Press. 
Hutchins, E. (2010). Cognitive ecology. Topics in Cognitive Science, 2(4), 705-715.

Ihde, D. (1990). Technology and the lifeworld: From garden to earth. Bloomington, Indiana: Indiana University Press.

Ihde, D., \& Malafouris, L. (2019). Homo faber revisited: Postphenomenology and material engagement theory. Philosophy \& Technology, 32(2), 195-214.

Kisely, S., Li, A., Warren, N., \& Siskind, D. (2018). A systematic review and meta-analysis of deep brain stimulation for depression. Depression and Anxiety, 35, 468-480.

Kirsh, D. (1995). The intelligent use of space. Artificial Intelligence, 72, 1-52.

Kirsh, D., \& Maglio, P. (1994). On distinguishing epistemic from pragmatic action. Cognitive Science, 18, 513549.

Kramer, A., Guillory, J., \& Hancock, J. (2014). Experimental evidence of massive-scale emotional contagion through social networks. Proceedings of the National Academy of Sciences of the United States of America, $111(24), 8788-8790$.

Krueger, J., \& Szanto, T. (2016). Extended emotions Extended emotions. Philosophy Compass, 11(12), 863-878.

Laland, K., Odling-Smee, J., \& Feldman, M. (2000). Niche construction, biological evolution, and cultural change. Behavioral and Brain Sciences, 23, 131-175.

Latour, B. (2005). Reassembling the social: An introduction to actor-network theory. Oxford, England: Oxford University Press.

Merleau-Ponty, M. (1965). Phenomenology of perception. London, England: Routledge.

Miller, B., \& Record, I. (2013). Justified belief in a digital age: On the epistemic implications of secret Internet technologies. Episteme, 10(2), 117-134.

Mittelstadt, B., Allo, P., Taddeo, M., Wachter, S., \& Floridi, L. (2016). The ethics of algorithms: Mapping the debate. Big Data \& Society, 3(2). https://doi.org/10.1177/2053951716679679

Mueller, P.A., \& Oppenheimer, D.M. (2014). The pen is mightier than the keyboard: Advantages of longhand over laptop note taking. Psychological Science, 25(6), 1159-1168.

Newen, A., De Bruin, L., \& Gallagher, S. (Eds.) (2018). The Oxford handbook of 4E cognition. Oxford, England: Oxford University Press.

Nguyen, C. T. (2020). Echo chambers and epistemic bubbles. Episteme, 17(2), 141-161.

Nickerson, R. (2005). Technology and cognition amplification. In R. Steinberg \& D. Preiss (Eds.), Intelligence and technology: The impact of tools on the nature and development of human abilities (pp. 3-27). London, England: Lawrence Erlbaum Associates.

Norman, D. (1991). Cognitive artifacts. In J. Carroll (Ed.), Designing interaction: Psychology at the humancomputer interface (pp. 17-38). Cambridge, England: Cambridge University Press.

Norman, D. (1993). Things that make us smart: Defending human attributes in the age of the machine. New York: Basic Books.

Peirce, C. S. (1935a). The collected papers of Charles S. Peirce Vol 2. Boston, MA: Harvard University Press.

Peirce, C. S. (1935b). The collected papers of Charles S. Peirce Vol 3. Boston, MA: Harvard University Press.

Piredda, G. (2020). What is an affective artifact? A further development in situated affectivity. Phenomenology and the Cognitive Sciences, 19(3), 549-567.

Piredda, G., \& Di Francesco, M. (2020). Overcoming the past-endorsement criterion: Toward a transparency-based mark of the mental. Frontiers in Psychology, 11, 1278. https://doi.org/10.3389/fpsyg.2020.01278

Preston, B. (2013). A philosophy of material culture: Action, function, and mind. New York: Routledge.

Preston, B. (2018). Artifact. In E. Zalta (Ed.), Stanford encyclopedia of philosophy. Available from https://plato. stanford.edu/entries/artifact/

Rietveld, E., \& Kiverstein, J. (2014). A rich landscape of affordances. Ecological Psychology, 26, 325-352.

Robbins, P., \& Aydede, M. (Eds.). (2008). The Cambridge handbook of situated cognition. Cambridge, England: Cambridge University Press.

Saarinen, J. (2020). What can the concept of affective scaffolding do for us? Philosophical Psychology, 33(6), $820-839$. 
Scarantino, A., \& de Sousa, R. (2018). Emotion. In E. Zalta (Ed.), Stanford encyclopedia of philosophy. Available from https://plato.stanford.edu/entries/emotion/

Schettler, A., Raja, V., \& Anderson, M. (2019). The embodiment of objects: Review, analysis, and future directions. Frontiers in Neuroscience, 13, 1332. https://doi.org/10.3389/fnins.2019.01332

Sennett, R. (2008). The craftsman. London, England: Penguin Books.

Simpson, D. (2012). Evaluating Google as an epistemic tool. Metaphilosophy, 43(4), 426-445.

Slaby, J. (2014). Emotions and the extended mind. In C. von Scheve \& M. Salmella (Eds.), Collective emotions: Perspectives from psychology, philosophy, and sociology (pp. 32-46). Oxford, England: Oxford University Press.

Smart, P., Clowes, R., \& Heersmink, R. (2017). Minds online: The interface between Web science, cognitive science, and the philosophy of mind. Foundations and Trends in Web Science, 6(1-2), 1-234.

Smart, P., Heersmink, R., \& Clowes, R. (2017). The cognitive ecology of the Internet. In S. Cowley \& F. ValléeTourangeau (Eds.), Cognition beyond the brain: Computation, interactivity and human artifice. ( 2 nd ed., pp. 251-282). Dordrecht, The Netherlands: Springer.

Smart, P., \& Shadbolt, N. (2018). The world wide web. In J. Chase \& D. Coady (Eds.), Routledge handbook of applied epistemology. New York: Routledge.

Solsman, J. (2018). YouTube's AI is the puppet master over most of what you watch. Available from https://www. cnet.com/news/youtube-ces-2018-neal-mohan/

Srinivasan, S., Diaz, M., Carty, M., \& Herr, H. (2019). Towards functional restoration for persons with limb amputation: A dual-stage implementation of regenerative agonist-antagonist myoneural interfaces. Scientific Reports, 9, 1981.

Sterelny, K. (2003). Thought in a hostile world: The evolution of human cognition. Oxford, England: Blackwell.

Sternberg, R., \& Preiss, D. (Eds.) (2005). Intelligence and technology: The impact of tools on the nature and development of human abilities. London, England: Lawrence Erlbaum Associates.

Sutton, J. (2010). Exograms and interdisciplinarity: History, the extended mind, and the civilizing process. In R. Menary (Ed.), The extended mind (pp. 189-225). Cambridge, MA: MIT Press.

Sutton, J. (2016). Scaffolding memory: Themes, taxonomies, puzzles. In C. Stone \& L. Bietti (Eds.), Contextualizing human memory: An interdisciplinary approach to understanding how individuals and groups remember the past (pp. 187-205). New York: Routledge.

Teunisse, W., Youssef, S., \& Schmidt, M. (2019). Human enhancement through the lens of experimental and speculative neurotechnologies. Human Behavior and Emerging Technologies, 1(4), 361-372.

Tribble, E., \& Sutton, J. (2011). Cognitive ecology as a framework for Shakespearean studies. Shakespeare Studies, 39, 94-103.

Turkle, S. (Ed.). (2007). Evocative objects: Things we think with. Cambridge: MIT Press.

Turner, R. (2014). Programming languages as technical artifacts. Philosophy \& Technology, 27(3), 377-397.

Yadav, D., Yadav, S., \& Veer, K. (2020). A comprehensive assessment of brain computer interfaces: Recent trends and challenges. Journal of Neuroscience Methods, 346, 108918.

Vaccari, A. (2016). Against cognitive artifacts: Extended cognition and the problem of defining 'artifact'. Phenomenology and the Cognitive Sciences, 16, 879-892.

Vaesen, K. (2012). The cognitive bases of human tool use. Behavioral and Brain Sciences, 35, 203-218.

Van Dijck, J. (2013). 'You have one identity': Performing the self on Facebook and Linked In. Media, Culture \& Society, 35(2), 199-215.

Viola, M. (2021). Three varieties of affective artifacts: Feeling, evaluative and motivational artifacts. Phenomenology and Mind.

Wheeler, M. (2019). The reappearing tool: Transparency, smart technology, and the extended mind. AI \& Society, 34(4), 857-866).

Zanker, M., Rook, L., \& Jannach, D. (2019). Measuring the impact of online personalisation: Past, present, and future. International Journal of Human-Computer Studies, 131, 160-168. 